\title{
EVA DUARTE EN ESPAÑA: REPERCUSIÓN Y PROPAGANDA DE UNA VISITA POLÍTICA. (1947-1948)*
}

\author{
EVA DUARTE IN SPAIN: REPERCUSSION AND PROPAGAND \\ OF A POLITICAL VISIT (1947-1948)
}

\author{
EVA DUARTE NA ESPANHA: REPERCUSSÃO E PROPAGANDA \\ DE UMA VISITA POLÍTICA (1947-1948)
}

\author{
VANESSA TESSADA SEPÚLVEDA** \\ Universidad Autónoma de Chile \\ https://doi.org/10.46553/EHE.23.1.2021.p77-95
}

\begin{abstract}
Resumen
Este artículo busca analizar el viaje de Eva Duarte de Perón a España en 1947 en el marco de la alianza forjada entre Argentina y España durante el período post Segunda Guerra Mundial. Se propone que la visita de Eva Duarte, pese a encontrarse supeditada a un apretado protocolo y agenda pro-hispanista por parte del régimen franquista, que quedó plasmado en la prensa escrita y audiovisual, logró representar el ideario político peronista centrado en la justicia social. La documentación analizada (prensa española y argentina y proveniente del Archivo Histórico de la Cancillería Argentina) permitiría dar cuenta de las repercusiones de su viaje reflejadas en la construcción de una representación hispanista y católica de Eva Duarte, la respuesta de la oposición en el exilio cuyas acusaciones recayeron en su carácter fascista y la prolongación de las ayudas, a partir de la creación de centros clínicos gratuitos en territorio español.
\end{abstract}

Palabras clave

Hispanismo - propaganda - Eva Duarte - Franco - peronismo.

\begin{abstract}
This article seeks to analyze the consequences of Eva Duarte de Perón's trip to Spain in 1947 in the framework of the alliance forged between Argentina and Spain during the post-World War II period. It is proposed that Eva Duarte's visit, despite being subject to a tight protocol and pro-Hispanic agenda by the Franco regime, that was reflected in the written and audiovisual press, managed to the Peronist political ideology focused on social justice. The documentation analyzed (Spanish and Argentine press and from the Historical Archive of the Argentine Foreign Ministry) would allow to account for the repercussions of your trip reflected in the construction of Hispanicist and Catholic representation of Eva Duarte, the response of the opposition in exile whose accusations fell on his fascist character and the extension of the aid, starting with the creation of free clinical centers in Spanish territory.
\end{abstract}

\section{Keywords}

Hispanism - propaganda - Eva Duarte - Franco - Peronism.

\footnotetext{
${ }^{*}$ Fecha de recepción del artículo: 13/11/19. Fecha de aceptación: 18/3/2020.

** Profesora Asistente, Pedagogía en Historia, Geografía y Ciencias Sociales, Universidad Autónoma de Chile, Av. Libertador Bernardo O'Higgins 1058, Santiago de Chile, ORCID: https://orcid.org/0000-0003-2884-5710 , vanessa.tessada@uautonoma.cl.
} 


\section{Resumo}

Este artigo busca analisar a viagem de Eva Duarte de Perón à Espanha em 1947 no marco da aliança firmada entre Argentina e Espanha no pós-Segunda Guerra Mundial. Propõe-se que a visita de Eva Duarte, apesar de estar sujeita a um rígido protocolo e agenda pró-hispânica do regime de Franco, que se refletiu na imprensa escrita e audiovisual, conseguiu representar a ideologia política peronista voltada para a justiça social. A documentação analisada (imprensa espanhola e argentina e do Arquivo Histórico da Chancelaria Argentina) permitiria dar conta das repercussões de sua viagem refletidas na construção de uma representação hispânica e católica de Eva Duarte, a resposta da oposição no exílio cuja As denúncias recaíram sobre o seu caráter fascista e a extensão da ajuda, desde a criação de centros clínicos gratuitos em território espanhol.

\section{Palavras chave}

Hispanismo - propaganda - Eva Duarte - Franco - peronismo.

\section{Introducción: El viaje de Eva de Perón como una apuesta de la propaganda}

La visita de Eva Duarte de Perón a España en 1947 no pasó desapercibida dado el gran impacto que tuvo en la prensa española. La parafernalia de la gira formó parte del plan de propaganda exterior y de transformaciones políticas interiores que la dictadura española desplegó para maquillar su carácter fascista, pues Franco necesitaba para su sobrevivencia el "oscurecimiento relativo de aquello que representaba más visiblemente el fascismo en el régimen, es decir, la Falange." 1 Desde el establecimiento de las Cortes (1942), la prohibición de saludar con el brazo en alto (1945) hasta el referéndum y promulgación de las leyes de sucesión (1947), el plan franquista consistió en legitimar el régimen ante un escenario internacional de postguerra alineado con las democracias occidentales vencedoras de la Guerra Mundial.

Esta estrategia se puso en funcionamiento tanto por la condena internacional propiciada por la Organización de Naciones Unidas debido al origen espurio y el carácter fascista del régimen español, como por la crisis económica en que estaba sumido el país producto de la posguerra y la política económica autárquica defendida por el Movimiento. De ahí, que la mano amiga de Argentina permitió proyectar la sobrevivencia del régimen en tanto aplacaba la profunda depresión económica y generaba espacios de propaganda internacionales para el Caudillo y sus políticas. Como dicen Rodríguez y Pardo la mantención del régimen franquista estuvo condicionada al éxito de la política exterior que Franco estableciera. ${ }^{2}$

En este sentido, la ayuda de Argentina fue fundamental en los primeros años de postguerra mundial. En el plano internacional, se tradujo en el apoyo del país ante la "cuestión española" tratada en la Organización de las Naciones Unidas (ONU) y en lo económico, en el establecimiento de convenios cuyos efectos fueron inmediatos en España. Esta relación, que tuvo usos políticos y propagandísticos para ambos gobiernos, fue coronada con el viaje de Eva Duarte de Perón el año 1947. Esta visita ha sido investigada principalmente desde la arista biográfica de Eva Perón, en tanto se constituye en un importante episodio de su carrera política, y por ello, se ha leído con el mismo maniqueísmo

\footnotetext{
${ }^{1}$ THOMÀS I ANDREU, 1999, 53.

${ }^{2}$ RODRÍGUEZ y R. PARDO SANZ, 1999
} 
que ha rondado las interpretaciones sobre el accionar personal y político de Eva Duarte. ${ }^{3}$ Desde otra perspectiva, la visita de la primera dama argentina ha sido incluida como una estrategia política diplomática que, utilizando la construcción de "lo hispánico", tuvo por objetivo generar un acercamiento al escenario internacional reacio a lo español y obtener réditos políticos gracias a la conversión de esta visita oficial en un espectáculo para las masas. ${ }^{4}$ Es en esta segunda línea donde se enmarca esta investigación que pone el acento en el análisis de distintos tipos de prensa y comunicaciones diplomáticas argentinas para dar cuenta de los usos propagandísticos que se hicieron de la visita de Eva Duarte y la recepción que tuvo, tanto entre las colonias de argentinos apostados en España, como de los exiliados republicanos y opositores a Franco.

De esta manera, entenderemos la visita de Eva Duarte a España como una acción propagandística utilizada tanto por Franco para levantar la idea de Hispanidad y comunión Hispanoamericana, como por Perón en los intentos de posicionarse internacionalmente. Sin dejar de lado, que la construcción discursiva en torno a la figura de Eva Duarte tuvo una arista ambivalente pues, al mismo tiempo que era objetualizada y convertida en espectáculo de la propaganda hispanista, el viaje la posicionaba como una figura política de importancia en la construcción y encarnación del peronismo. Una representatividad política que veremos también reflejada en la prensa opositora que criticó duramente la presencia de la primera dama argentina en Europa. La recepción que las colonias argentinas hicieron de la visita sublimó en la figura de la primera dama un sentimiento de orgullo nacionalista derivado de la ayuda que Argentina otorgaba a España y lo volcó en una serie de iniciativas de beneficencia que hacían eco de la justicia social peronista. Este análisis se realizará a partir de la revisión de prensa española (periódico $A B C$, noticiario filmado NO-DO), prensa opositora española (España Popular, Euzkadi Roja, Mundo Obrero y Mujeres Antifascistas Españolas); del diario Clarín, de la prensa argentina y documentación del Fondo Embajada en Madrid presente en el Archivo Histórico de la Cancillería de Argentina.

\section{La relación hispano-argentina hacia finales de los cuarenta.}

El veto internacional impuesto a España durante la postguerra mundial obligó al gobierno a idear estrategias no tradicionales de acercamiento diplomático. El Ministerio de Asuntos Exteriores tuvo que plantear alternativas que interpelaran lo cultural por sobre lo político, pese a que el objetivo ulterior de las iniciativas diplomáticas fuera la integración del régimen franquista en el escenario internacional. ${ }^{5}$ De manera que, una parte importante de la relación diplomática con Hispanoamérica se hizo a partir de esfuerzos que la diplomacia cultural llevó adelante. ${ }^{6}$

Para aquel proceso de incorporación española, América Latina se presentó como el espacio geográfico de proyección natural de la península, al que estaba unido cultural y espiritualmente gracias al pasado e historia común que cimentaba la construcción de "Hispanoamérica". Esta lectura de la "Hispanidad" propuesta por el nacionalcatolicismo español radicó en el ideario de Ramiro de Maeztu, para quien España tenía una misión

\footnotetext{
${ }^{3}$ ZANATTA, 2012; MICHELOTTI-CRISTÓBAL, 1998; GONZÁLEZ DELUCA, 2000; YÁÑEZ, 2013; NAVARRO, 1994; 2012.

${ }^{4}$ GÓMEZ-FERRER, 2012; PELTA, 2005; REIN, 1995; CORREYERO-RUIZ, 2003; EIROA, 2012.

${ }^{5}$ DELGADO, 1988.

${ }^{6}$ Ibidem.
} 
histórica que cumplir en suelo americano y guiada por la providencia actuar como una guía de la relación compartida. La amalgama cultural de la Hispanidad estaba compuesta por la religión, el catolicismo, el lazo histórico colonial civilizatorio y características comunes como el idioma castellano y la cultura del siglo de oro. ${ }^{7}$ Bajo esta lógica, las relaciones con América Latina posicionarían a España en su antiguo sitial de puente entre América y Europa y servirían para romper el ostracismo internacional a partir de la creación de un área de prestigio para España bajo la idea de "Comunidad Hispánica de Naciones". El liderazgo de esta "Comunidad" revertiría la desmedrada posición española en el concierto internacional.

Estos esfuerzos resultaron fallidos en la interpretación de Celestino del Arenal ${ }^{8}$; mientras que Lorenzo Delgado argumenta que dado el carácter utilitario de estas políticas culturales sus resultados fueron más bien cosméticos durante sus primeros años de implementación. ${ }^{9}$ Debemos tener en cuenta que el aislamiento de España se confirmó rápidamente tras el fin de la Segunda Guerra Mundial. En 1946, la ONU votó la Resolución 39 que obligaba al retiro de los embajadores de los países suscritos e impedía a España formar parte de las nuevas organizaciones supranacionales de postguerra. Y no fue sino hasta 1950 (con la Resolución 386) cuando se produjo el primer relajamiento de la "cuestión española" que permitió el retorno de los embajadores y la participación en algunas organizaciones internacionales, lo que condujo finalmente a la integración española en la ONU en 1955.

En este escenario de exclusión internacional, la relación que Franco tuvo con Argentina devino en un puntal de apoyo para la sobrevivencia del régimen. Pues, no solo lo avaló con su defensa ante la ONU, la mantención del Embajador y la visita de la primera dama, sino porque este lazo sostuvo económicamente al país en momentos en que atravesaba una profunda crisis. En este sentido, para R. Rein solo la ayuda argentina permite explicar la sobrevivencia de Franco en el período comprendido entre 1946 y $1949^{10}$, especialmente por el auxilio económico que fue mucho más relevante para Franco que cualquier apoyo diplomático que España pudiera obtener. ${ }^{11}$

La asistencia argentina comenzó en 1946 (octubre) cuando se pactó entre ambos países el Convenio Comercial y de Pagos, que establecía el otorgamiento de préstamos por parte de Argentina para comprar grano del mismo país. En 1947, el embajador argentino Pedro Radio presentó sus credenciales a Franco y se instaló en Madrid contraviniendo la Resolución $39^{12}$ y en junio de ese año se produjo la visita de la esposa del presidente, Eva Duarte. La relación mostró su consolidación cuando Franco recibió un segundo golpe internacional con el anuncio de la exclusión de España del Plan Marshall para la reconstrucción de Europa. Esta segunda embestida fue el acicate para la firma de un nuevo acuerdo y en abril del 48 se concretó el Protocolo Franco-Perón, el que vino a reforzar la importación de cereal, buscando asegurar el suministro hasta 1951. En octubre de ese mismo año, el Ministro de Asuntos Exteriores español Alberto Martín Artajo visitó Argentina, al igual que los Coros y Danzas de España. Esta estrecha relación se desbarató rápidamente cuando a principios de los 50 Perón suspendió el convenio y cesó el envío de cereales a la península.

Esta dinámica relación sirvió de propaganda a ambos países en un contexto donde tanto España como Argentina mantenían relaciones tensas con Estados Unidos, rechazaban el

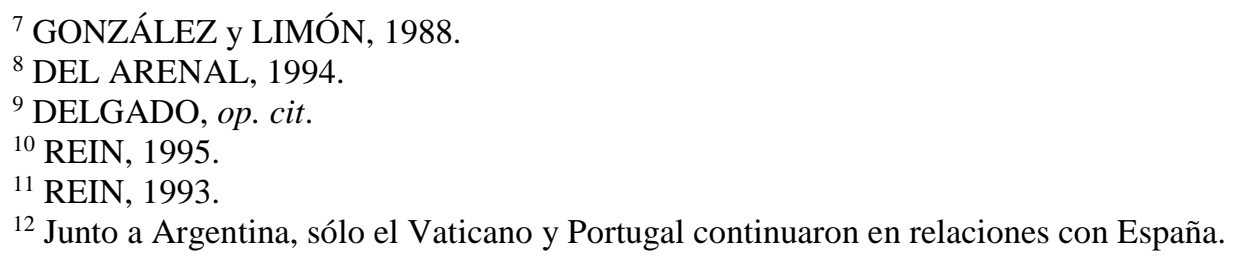


mundo comunista y buscaban aunarse en la imagen de una Europa católica. ${ }^{13}$ Además, existía de parte de Perón simpatía ante un régimen dirigido por un militar, fuerte y anticomunista, cuya amistad le permitía romper con la dirección tradicional centro - periferia de las relaciones internacionales de ayuda mutua. Por su parte, gracias a esta relación, Franco quebraba el boicot diplomático internacional y perfilaba el discurso hispanista como sustrato ideológico de la propaganda postguerra. Asimismo, ambos países perseguían romper con el aislamiento en que estaban sumidos, Argentina tras la mantención de la neutralidad durante la Segunda Guerra ${ }^{14}$ y España alejada de las democracias occidentales, tiñendo esta relación con una arista política, además de la puramente económica.

Por lo tanto, como argumenta Rein, esta cooperación debe ser analizada desde los intereses complementarios y circunstanciales de ambos países, más allá de las puras motivaciones ideológicas. ${ }^{15}$ De hecho, sabemos que durante los primeros años 50 la alianza se resquebrajó por el viraje discursivo de Perón hacia la latinidad y por las presiones de grupos internos argentinos que se declararon contrarios al régimen franquista. A su vez, el anticomunismo franquista encajaba en el nuevo escenario discursivo de la Guerra Fría y el régimen español se abría paso en el escenario internacional, dejando en un lugar secundario las relaciones con América Latina y la necesidad del apoyo argentino.

\section{Representaciones de Eva: claves para la lectura de su viaje a España}

Como discute profusamente la historiografía, la figura de Eva Perón ha sido construida y reconstruida, incluso antes de su prematura muerte. Una verdadera mitología sustentada por todo tipo de géneros que van desde las biografías históricas hasta el teatro. ${ }^{16}$ Sin embargo, tras su muerte, propone M. Navarro, vemos perfilarse dos versiones de Eva, una, la Evita buena, cuya construcción se hizo a partir de obras de corte hagiográfico que la adjetivaron con características femeninas católicas (hermosa, espiritual, abnegada, generosa, incansable, sacrificada ${ }^{17}$ ). La propaganda peronista repitió esta imagen y es la que también se plasma en su autobiografía. ${ }^{18}$ Esta representación consolida una figura ficticia, cuyas características más sobresalientes fueron, al decir de Michelotti-Cristobal, la artificialidad y el melodrama ${ }^{19}$, que convierten a Eva -muchas veces- en una figura cosificada, en un espectáculo.

La segunda representación, la "Antievita", supone una mirada contrapuesta a la Eva santificada, cuya construcción comenzó durante la década de los cuarenta de la mano de sus detractores y se intensificó tras su muerte. ${ }^{20}$ En esta interpretación se critica su origen popular y la carrera actoral que desarrolló hasta unirse a Perón. Este pasado dudoso está envuelto en calificaciones de mujerzuela, vulgar y mala actriz. Pero, sobre todo, es retratada como una mujer ambiciosa y manipuladora "que encarnaba todo lo peor del peronismo -la chusma en el poder." 21 . Esta imaginería de la Antievita reforzó la idea de que su participación política

\footnotetext{
${ }^{13}$ ZANATTA, 2012.

${ }^{14}$ NAVARRO, 1994

${ }^{15}$ REIN, 1993, 201.

${ }^{16}$ NAVARRO, 2012

17 Ibidem, 116.

${ }^{18}$ Nos referimos a La razón de mi vida.

${ }^{19}$ MICHELOTTI-CRISTÓBAL, 1998, 136.

${ }^{20}$ Se refiere principalmente al texto La mujer del látigo, de Mary Main.

${ }^{21}$ NAVARRO, op. cit., 120.
} 
radicaba en su deseo de venganza contra las clases oligarcas y que su poder de manipulación la ponían por sobre Perón en las decisiones del país. ${ }^{22}$

Ambas construcciones posicionan a Eva Duarte en un espacio de participación políticapública ambiguo. La visión opositora castiga el papel político asumido por la primera dama que es entendido como una intromisión en un mundo masculino para el que no está preparada y en el que las formas que usa son inapropiadas para una mujer. ${ }^{23}$ Los obstáculos impuestos a su desenvolvimiento político responden a prejuicios asentados en la división tradicional de las esferas masculinas y femeninas (subestimación de sus habilidades políticas por el hecho de ser mujer), pero también hay un ingrediente de clase, en la medida que su proveniencia social no la habilitaba para codearse con las elites nacionales e internacionales. ${ }^{24}$ En la orilla contraria, respecto de su representación política, la figura de Eva Duarte supuso un quiebre en el papel que la mujer tradicionalmente había tenido en política, pues la construcción peronista vino a presentar una nueva feminidad "con un pie anclado en el ámbito privado y otro en el público." ${ }^{25}$ A esto, hay que agregar que el liderazgo construido por Eva se configuró de manera individual, por lo que estaba vetado a otras mujeres.

El liderazgo de Evita no solo se levantó en torno a un discurso político, que Eva se apropió desde el peronismo y que tradujo con simplicidad, uso de la repetición y una sensibilidad que feminizaron su expresividad, sino que también estuvo apoyado por la puesta en funcionamiento de recursos que le permitieron ganar adhesión popular. González Deluca menciona, por ejemplo, el programa de ayuda social y los donativos sin límites que hacía la primera dama, que mejoraron la relación con los sectores populares y trabajadores; el contacto directo tanto verbal como físico con la gente, enfermos, ancianos, niños y necesitados; una entrega total al trabajo de parte de Eva; su atractivo físico; los elogios constantes a Perón; y, la explotación de la condición femenina, en la que hacía uso de una apuesta discursiva que reforzaba la división tradicional de roles sociales. ${ }^{26}$

Esta diversidad de figuraciones sobre Eva Duarte, esos elementos definitorios de su presencia en el espacio público, tanto aquellos elementos que se asociación específicamente a su carisma y liderazgo como aquellos que conforman la "Antievita", los encontramos en las representaciones que la prensa realizó del viaje de la primera dama, cuyas principales características fueron su naturaleza propagandística y política.

\section{El viaje de Evita: entre la propaganda y la imagen política.}

Si bien la invitación oficial a España había sido cursada a Juan Domingo Perón, su renuencia a viajar a Europa fue suplida con la figura de Eva Duarte, cuya presencia de igual manera reforzaría el acercamiento hispano-argentino y consolidaría la política de apoyo establecida, además de ser la primera tras el aislamiento internacional impuesto a España. ${ }^{27}$ Eva para ese momento ya poseía prestigio e influencia política que la habilitaba para representar a su país y a Perón en el extranjero. ${ }^{28}$ Sin embargo, este reemplazo tuvo oposición en el país. La Cancillería se mostró negativa, pues sostuvieron que un acercamiento a la

\footnotetext{
22 Ibidem, 118.

${ }^{23}$ NAVARRO, op. cit., 130.

${ }^{24}$ MICHELOTTI-CRISTÓBAL, op. cit., 199.

${ }^{25}$ NAVARRO, op. cit., 126.

${ }^{26}$ GONZÁLEZ DELUCA, op. cit., 204.

${ }^{27}$ EIROA, op., cit, 119.

${ }^{28}$ ZANATTA, 2012.
} 
España fascista correspondía a un retroceso en el posicionamiento internacional argentino, especialmente a los intentos de acercamiento con EE. UU. ${ }^{29}$ De ahí la insistencia en que la gira se extendiera a otros países europeos, además de España.

Asimismo, la oligarquía del país ponía en duda la capacidad de la primera dama para llevar adelante con éxito un viaje de estas características, sobre todo atacaron la poca preparación de Eva, su falta de protocolo y educación, además de los gastos que implicaba el viaje, incluyendo las compras superficiales en los que se incurrió, como, por ejemplo, de modelos de alta costura. ${ }^{30}$ Es más, se acusó que las motivaciones de Eva pasaban por una sed de venganza contra la oligarquía ${ }^{31}$ e incluso se le acusó de tener intención de conformar un "eje" Franco - Perón, reavivando el halo pro-fascista que envolvió la relación.

En la España franquista, si bien la visita se esperaba con ansias, el descontento radicó de manera importante en el costo desmedido de la visita. Además, hubo aprensión por parte de los círculos más conservadores, quienes temían la cercanía que Eva podría mostrar con los obreros. También parte del mundo católico se sentía a disgusto con las formas de Eva y su pasado, de hecho, fue ignorada por el clero católico y una parte de la aristocracia. ${ }^{32}$

Pese a las mencionadas críticas y obstáculos, la pareja Perón insistió en la realización del viaje, a pesar de no haber aclarado debidamente su objetivo. ${ }^{33}$ Eva Duarte hizo frente a las críticas, sobre todo aquellas que ponían en duda su capacidad de representar políticamente el país, situándose desde un discurso feminizado desde donde emergió como "embajadora de la paz" cuya misión era tender un arcoíris de paz entre los pueblos. Esta estrategia discursiva utilizó una retórica maternalista y femenina y desde allí abordó su representación en el espacio público. Además, y como una manera de despejar las dudas sobre las intenciones del viaje a España, se le sumaron otros destinos: Italia, Inglaterra (que finalmente no se concretó), Francia, Portugal y Suecia. El carácter de estas visitas tuvo tintes políticos, en Italia fue recibida por el Papa y el Ministro de Relaciones Exteriores; en Portugal tuvo audiencia con el presidente Fragoso Carmona y se entrevistó, además, con Juan de Borbón; y en Francia se reunió con el presidente Vincent Auriol. Pese a estos encuentros que otorgaban consistencia al viaje, las protestas a su visita las trocaron en estadías de bajo perfil.

Debido a esos traspiés, la prensa tanto argentina como hispana centró su mirada en la apoteósica visita a España, destacando su carácter cultural en actividades ligadas al hispanismo, la religión y la ayuda argentina. ${ }^{34}$ Una línea propagandística que había tenido un preludio simbólico cuando en diciembre de 1946, una Misión Argentina condecoró a Franco con la Orden del Libertador San Martín. ${ }^{35}$ Y prosiguió en marzo del $47^{36}$ con la invitación para la visita oficial y la negociación de la concesión de la Gran Cruz de la Orden Isabel la Católica a Eva Perón, la que fue decretada en abril de ese año. ${ }^{37}$ Sumado a la condecoración, comenzó en España una frenética búsqueda de los restos de los padres del General San

\footnotetext{
${ }^{29}$ NAVARRO, 1994, 154.

30 Ibidem, 156.

31 Ibidem, 153.

${ }^{32}$ REIN, 1995, 59.

${ }^{33}$ NAVARRO, op. cit., 153.

${ }^{34}$ Hay que considerar que la prensa española en este período no mantuvo grandes diferencias ideológicas ni discursivas, sobre todo por la censura y el ambiente político español. Además, de que la principal fuente de información fue el periódico monárquico $A B C$ y recortes de periódicos del Movimiento. CERRANO, $2007,94$.

${ }^{35}$ AHMREC, Fondo Embajada en Madrid, AH/003, Carta, 20 de diciembre de 1946.

${ }^{36}$ Ibidem, Telegrama №37, 13 de marzo de 1947.

${ }^{37}$ Ibidem, Telegrama No50 ,1 de abril de 1947.
} 
Martín, los cuales fueron encontrados y enviados a Argentina en agosto de 1947, celebrando el lazo hispanista histórico que unía a ambos países. ${ }^{38}$

El objetivo propagandístico de la visita para el régimen franquista puede entenderse a partir de lo que Beatriz Correyero ha denominado "propaganda turística". Con este concepto, la autora enmarca las invitaciones que el gobierno de Franco comenzó a cursar a distintos tipos de personalidades internacionales desde mediados de los cuarenta. En tanto -como hemos visto- los cauces diplomáticos tradicionales se encontraban empantanados para la causa española "el turismo pasó a convertirse en un instrumento más de la política de Estado del Gobierno de Franco". ${ }^{39}$ El objetivo de esta "propaganda turística" era romper el cerco internacional y mostrar a una España moderna y tranquila. De hecho, dice Correyero, la visita de Eva Perón fue una de las que causó mayor expectación y cobertura mediática, lo que evidenciaba, por lo menos hacia el exterior, la existencia de adhesión popular hacia Franco. ${ }^{40}$ En este sentido, la apuesta propagandística formó parte del intento del Generalísimo de levantar una imagen de líder popular, desmilitarizar su figura ${ }^{41}$ y desviar la atención de las masas de la dureza, pobreza e ilegitimidad del régimen. De ahí que, a pesar de las críticas que, por ejemplo, apuntaban al excesivo costo del viaje, el gasto se entendió como una inversión que dejaba a España unida a Argentina ${ }^{42}$, servía de propaganda y levantaba ese perfil popular necesario en momentos en que se producía la campaña del referéndum de Sucesión que se realizaría por esas mismas fechas. ${ }^{43}$

Esta “propaganda turística” también permitía exhibir los logros de la gestión del régimen y mostrar una imagen mejorada con respecto al período de postguerra civil. Tal como afirma Matilde Eiroa, estas visitas daban a Madrid la oportunidad de mostrarse como un modelo político alternativo a los ojos de los visitantes y potenciar la imagen del país frente a los países de América Latina ${ }^{44}$. De manera que, pese a la impronta cultural del viaje, no podemos rehuir el carácter político que le otorgaron los objetivos, anhelos y símbolos que lo configuraron. ${ }^{45}$

El viaje de Eva por España se prolongó por 18 ajetreados días, en los cuales la primera dama recorrió Andalucía, Madrid, Ávila, Toledo, Galicia, Aragón y Cataluña. Cada paso de Eva fue documentado y las características apoteósicas y el recibimiento caluroso por parte del pueblo español fue expresado en repetidas oportunidades, lo que puede ser considerado un triunfo propagandístico. La respuesta a la presencia de Eva Perón sorprendió incluso a la legación chilena en Madrid que comunicaron al gobierno chileno que la visita había sido "de constantes agasajos, ceremonias, quizá únicas en España, homenajes en los que los nombres de Argentina y España figuraron millares de veces en boca de los españoles, en la prensa diaria y en las emisiones extraordinarias de radio". ${ }^{4}$

El éxito de la visita respondió no solo al esfuerzo que la prensa tuvo como encargada de construir el ambiente que permitió tal despliegue de gente y que facilitó y celebró las

\footnotetext{
${ }^{38}$ Ibidem, Telegrama No86, 15 junio 1947; Ibidem, Telegrama No 119, 25 de julio 1947.

${ }^{39}$ CORREYERO-RUIZ, 2003, 49.

${ }^{40}$ Ibidem, 51.

${ }^{41}$ REIN, 1995.

${ }^{42}$ EIROA, op., cit, 124.

${ }^{43}$ Ibidem.

${ }^{44}$ Ibidem.

${ }^{45}$ ZANATTA, 2012.

${ }^{46}$ AMINRE, Fondo Histórico 2560, Confidencial N²93/75, "Visita de Eva Perón”, 27 de junio de 1947, 1. (cursiva mía)
} 
aclamaciones populares a la visita; sino que la organización del viaje comprometió un programa bien nutrido de invitaciones, actos, ceremonias. Esta agenda abordó tres grandes áreas: el fundamento hispánico que unía a ambas naciones, el catolicismo como base de actuación de la misión de paz de Eva y el discurso de justicia social. Este sustento, que es reiterado una y otra vez por la prensa, comenzó a desplegarse en los mensajes transmitidos por Radio Nacional de España como preparativos del viaje:

"Era lógico, pues, que, como expresión de esa hermandad en la fe católica y en la política social, España acariciara la idea de agasajar en su suelo al paladín argentino de las reformas sociales, el General Perón, y a su dignísima esposa, la señora Eva Duarte de Perón, quién, al lado de su esposo, realiza la cruzada redentora del obrero con la misma inteligencia y noble feminidad con que en pasadas edades la Reina Isabel acompañara al Rey Fernando en la gesta emancipadora de España." 47

El carácter cultural, hispánico, religioso y la justicia social se fueron desarrollando y entrelazando a lo largo del viaje, siendo cada una de ellas evocadas constantemente en la cobertura del viaje. La prensa se encargó de crear los escenarios donde Eva Duarte aparece de múltiples maneras; es representada en su versión santificada, devota y humilde; es feminizada en su uso del espacio público a partir de la descripción de su vestimenta, actitudes y belleza; y es presentada como sujeto en el espacio público, aunque subordinada a un varón, en tanto es mencionada junto a quien la acompaña, ya sea un personero civil o militar del régimen, o nominalmente al llamarla "la esposa del presidente", "Sra. de Perón", "la esposa de Perón".

Sin lugar a duda, fue el hispanismo el hilo conductor de la visita y base del armatoste simbólico - ideológico a partir del cual se elaboró el programa. La hispanidad del viaje se volcó en el lenguaje utilizado para narrar la visita; también se notó en el paso por sitios históricos relevantes para la historia española y el siglo de oro (por ejemplo, El Escorial); y en la imposición de la Gran Cruz, oportunidad que Eva Perón aprovechó para elogiar a Isabel la Católica, atando su propia actuación política a la herencia hispánica:

"Legado de una Reina combativa y múltiple, que ayudó a visionarios y colaboró con caballeros de armas obcecados en su propia conquista de moros. Legado de una Reina que atendió a lo universal -la fe católica- y a lo temporal, la expansión de su reino cristiano. Legado de Isabel, la mujer que estuvo más cerca de Dios en el tiempo sagrado de España, cuando estar cerca de Dios era combatir y rezar. No otra cosa es para mí este símbolo." 48

En este sentido, la prensa española convirtió a Eva en un "ícono de la hispanidad", generando un espacio para el despliegue público de "los símbolos relacionados con esa hispanidad". ${ }^{9}$ El modelo de mujer que representa Eva en la prensa está en clave nacionalcatólica, es femenina, elegante y caritativa. Construcción que, para R. Pelta, la aleja del papel político que Eva Perón se estaba forjando en Argentina, como luchadora social, parte y cercana a los sectores populares y con un rol político activo. ${ }^{50}$ Por lo tanto, lo que

\footnotetext{
${ }^{47}$ AHMREC, Fondo Embajada en Madrid, AH/002 Carta que remite mensaje del Reverendo Padre Hernán Benítez pronunciado el 17 de abril en Radio Nacional de España, 19 de abril de 1947. 3 (cursiva mía)

48 "Amamos al corazón de España y a la Justicia", ABC Madrid, 10 junio 1947, 5.

${ }^{49}$ PELTA, 2005, 187.

${ }^{50}$ Ibidem.
} 
vemos en España es el uso de una retórica que feminiza su accionar público, sacándolo de la arena política tradicional masculina. Esta visión queda estampada en la opinión de Francisco de Cossío acerca de la visita de Eva, donde se reitera que la irrupción de la mujer en la política debía ser de la mano de valores femeninos, reforzando la misión de "embajadora de la paz" que Eva se atribuyó al comienzo de su viaje:

"La llegada de la señora de Perón a Madrid, que ha sido prueba irrefutable de la unidad de los españoles frente a la justicia y la injusticia que reciben del exterior, ha alcanzado cotos que rebasan todo lo previsible. Ello da una importancia extraordinaria de la mujer en la política y hasta qué punto, la pura presentación de una mujer, como mensajera de sentimientos e impulsos afectivos, puede tener una eficacia que le sería muy difícil conseguir a un hombre. ",51

Un segundo pilar importante fue la religiosidad de la viajera, lo que constituyó una parte importante de la cobertura periodística. En los servicios religiosos o en las visitas a diversos templos, la prensa la mostró profundamente emocionada o bien entregando importantes donaciones. De ahí que esta devoción fuera retribuida con distintos reconocimientos. ${ }^{52}$ Esta cercanía al mundo católico respondía a fines estratégico-políticos y a que parte del discurso público de Eva Perón se sustentó en valores tradicionalmente femeninos como la abnegación, el sacrificio maternal, así como a la diferencia complementaria entre los sexos, es decir, como nos dice D. Barrancos, se hacía parte del discurso más conservador sobre el papel social de las mujeres. ${ }^{53}$

Esta construcción de la Eva femenina, católica e hispanista se complementó con una imagen ligada a la defensa de la justicia social y todo aquello que el peronismo significaba para los sectores trabajadores argentinos. En este sentido, nos encontramos con momentos en que la primera dama quebró el encasillamiento hispanista, resaltando el papel de Perón, la justicia social y la hermandad entre trabajadores, por sobre la unión fundada en los lazos hispanistas entre ambos países. En esta línea, uno de los aspectos representativos será el constante contacto que Eva intentó mantener con los sectores populares y empobrecidos de España. Refieren en los periódicos argentinos los obsequios traídos por la mandataria para los más humildes, las distintas donaciones, atenciones y saludos y que incluso "prefirió rechazar algunos agasajos que se le habían preparado". ${ }^{44}$ Con esto, traía al escenario español,

\footnotetext{
${ }^{51}$ AHMREC, Fondo Embajada en Madrid, AH/001 Informe del Consulado. 17 de junio de 1947. DE COSSÍO, "Pasión Trasatlántica" Diario Faro de Vigo, 12 de junio de 1947 (cursiva es mía).

${ }^{52}$ Fue nombrada Camarera de honor de la Virgen de Granada y y se envió a Argentina una efigie de tamaño natural de la Virgen de las Angustias. Fue nombrada camarera mayor de la Virgen de la Esperanza, y posterior a su retorno a Argentina las hermanas de Jesús Nazareno y María Santísima del Rosario le concedieron a Eva el cargo de Camarera nuestra Padre Jesús Nazareno. El Hermano Mayor de la Venerable Hermandad de Nuestro Padre Jesús de la Caridad y María Santísima de Consolación y Amparo de Málaga concedió el cargo de Camarera Mayor Honoraria de la corporación a Eva Duarte, siendo el cargo femenino más alto posible en la corporación. Asimismo, se nombra a Eva Duarte Presidenta de Honor de la "Liga y Centro Social de la Virgen de Fátima" de Valladolid. Ver: BNA "Encuéntrase en Granada la Esposa del General Perón”, Clarín, 16 de junio de 1947, 4; AHMREC, Fondo Embajada en Madrid, AH/003, Carta, 10 junio 1948; Ibidem, AH/004 Carta, Barcelona 7 junio de 1948; Ibidem, AH/007 Carta Madrid 21 mayo de 1948.

${ }^{53}$ BARRANCOS, 2007, 185.

${ }^{54}$ BNA "Se muestra impresionada la señora de Perón por el homenaje recibido", Clarín, 11 de junio de 1947, 4.
} 
los gestos mediante los cuales construía liderazgo en Argentina ${ }^{55}$, entre los que estaba ser la intermediaria entre Perón y los descamisados. ${ }^{56}$

Sin embargo, los esfuerzos políticos desarrollados por Eva Perón seguían, incluso en la prensa argentina, tamizados por la feminización de su rol político. En los periódicos se afirmaba que Eva "se ha metido en un bolsillo al pueblo español" 57 , pero debido a su carisma y aspecto físico, dando cuenta de que aún la construcción de Eva Duarte en el espacio público estaba modulada desde su lugar de mujer. Decían los periódicos argentinos: "La exquisita simpatía que irradia toda su persona, su sonrisa deliciosa y la belleza juvenil de su rostro, (todo lo cual) han constituido un imán que ha servido para cautivar a los madrileños". ${ }^{58}$

A los gestos de ayuda hacia los necesitados que se sucedieron durante todo el viaje, se le sumaron los cargamentos de mercadería que fueron enviados a través de la Comisión Ejecutiva Nacional de Ayuda a los Pueblos Afectados por la Guerra ${ }^{59}$ y que serían repartidos entre el pueblo español. Estas ayudas fueron enviadas varias veces con distintos destinatarios. ${ }^{60}$ Desde el gobierno argentino entendían estas ayudas en torno a la propaganda, por lo que de manera oficial la representación diplomática se hacía cargo de la entrega. ${ }^{61}$ Asimismo, se repartieron ayudas al sector educativo, proveyendo de material a las escuelas que llevaran por nombre República Argentina y se anunció la entrega de un solar para la construcción del Instituto de la Argentina y del Colegio Mayor para los estudiantes universitarios argentinos. ${ }^{62}$

Por último, es necesario mencionar que el falangismo también se hizo parte de esta visita. Al pasar por El Escorial se conmemoró en la tumba de José Antonio Primo de Rivera y los Coros y Danzas de España hicieron una presentación dedicada a Evita en la Plaza Mayor de Madrid. Asimismo, conoció las distintas obras del falangismo, por ejemplo, las organizaciones juveniles, sobre todo las llevadas adelante por Sección Femenina. En este sentido, estuvo en el Castillo de la Mota y visitó la Granja de San Ildefonso en Segovia. Hay que tener en cuenta que el trabajo de Eva con los más pobres y trabajadores argentinos una vez asumido su rol como primera dama fue en crecimiento. Con el paso del tiempo se fue convirtiendo en la intermediaria entre Perón y los descamisados y para ello fueron fundamentales los servicios de ayuda a los más desfavorecidos, muchos de ellos similares a los implementados por la Sección Femenina de Falange. ${ }^{63}$

\footnotetext{
${ }^{55}$ GONZÁLEZ DELUCA, op. cit.

56 POTTHAST, 2010, 267.

${ }^{57}$ BNA "Se muestra impresionada la señora de Perón por el homenaje recibido", Clarín, 11 de junio de 1947, 4.

${ }^{58}$ Ibidem.

${ }^{59}$ AHMREC, Fondo Embajada en Madrid AH/001 Informe, 6 de junio 1947.

${ }^{60}$ Se enviaron para los damnificados por la catástrofe de Cádiz (1947) y para la delegación de Prensa en Madrid. Estas ayudas estaban constituidas por víveres, harina y maíz por toneladas. AHMREC, Fondo Embajada en Madrid, AH/003, 8 agosto 1947. Referido al envío de alimentos; Ibidem, 10 de enero de 1948.

${ }^{61}$ Ibidem, Carta, 3 junio 1947.

${ }^{62}$ AHMREC, Fondo Embajada en Madrid, AH/003 Telegrama Nº160, 12 de octubre 1947.

${ }^{63}$ BARRANCOS, op. cit., 183.
} 
La cobertura mediática también se documentó a través del NO-DO. ${ }^{64}$ El formato audiovisual de las informaciones sobre la visita de Eva Duarte ${ }^{65}$ presentará de manera mucho más vívido el entusiasmo de las muchedumbres, que se contaron por miles, y el engalanamiento de las ciudades que recibieron a la primera dama. El NO-DO generó información del paso de Eva Duarte por las Palmas, Madrid, Ávila, Medina del Campo, Segovia, San Lorenzo del Escorial, Toledo, Granada, Sevilla, Huelva, Santiago de Compostela, Vigo, Zaragoza y Barcelona. En cada uno de los noticiarios se declararán diversos aspectos y características del viaje en línea con la propaganda esbozada en la prensa escrita.

En primer lugar, los valores y características hispánicas sirven para describir cada paso del viaje, los lugares que Eva Perón visita y sus actitudes, lo que se acompaña con una fuerte tendencia a presentar su devoción religiosa. Por ejemplo, en la visita a Zaragoza, la primera dama asiste a una misa en la Catedral, las imágenes la muestran ingresando al servicio religioso y luego acercándose al altar donde yace la imagen de la Virgen del Pilar, Eva se arrodilla, entrega su ofrenda y besa la imagen, mientras el narrador comenta que "(...) en un momento de hondo fervor, visiblemente emocionada, (Eva) ha llegado hasta el trono de la Hispanidad (...)" ${ }^{66}$ Esta retórica se repite en varias de las ciudades, entrelazando religión, hispanidad y características femeninas. En este sentido, podemos colegir que el NO-DO construye un modo de habitar el espacio público por parte de Eva Perón, que la muestra grácil, elegante y con las emociones a flor de piel, destacando su fervor religioso, es decir, da continuidad a los patrones de la prensa escrita, que atribuye características femeninas a su papel social.

Asimismo, muchas veces se hace alusión al papel de "embajadora extraordinaria", dando cuenta con ello que estaba en representación de Argentina y el gobierno argentino. Son decidoras las menciones a que Eva simboliza a la Argentina y a la relación de ayuda que han mantenido en ambos países. La aclamación popular y los vítores gritan los nombres de Franco y Perón y flamean las banderas argentinas y españolas. En la locución de la gran manifestación sucedida en la Plaza de Oriente, dice el narrador: “(...) se concentran miles de almas para rendir a la Argentina, en la persona de Doña María Eva, su homenaje fervoroso". ${ }^{67}$

La masividad de las concentraciones realizadas debido a la visita queda explícita en el material audiovisual, demostrando el poder movilizador de masas que aún tenía la dictadura franquista. La apuesta audiovisual permite entender la construcción propagandística de la visita y la conversión de Eva Perón en un espectáculo del régimen. Esta masividad se capitalizó a partir del acompañamiento que importantes representantes del régimen, como ministros, militares y figuras públicas culturales y locales, hicieron a la primera dama argentina en cada uno de los compromisos de la visita. Las pocas veces que la vemos acompañada de otra mujer, ellas no son individualizadas, salvo si se trata de la esposa del

\footnotetext{
${ }^{64}$ NO-DO (Noticias y Documentales) fue un noticiero que de manera semanal se proyectaba en los cines españoles, durante el período comprendido entre 1943 y 1981. Fue creado en 1942 por la Vicesecretaría de Educación Popular, con la intención de "mantener, con impulso propio y directriz adecuada, la información cinematográfica nacional". Ver: Cronología NO-DO en URL: https://www.rtve.es/filmoteca/no-do/historia/ (Visitado el 31-07-2020)

65 "La primera dama argentina en España", NO-DO, 1947 en Filmoteca Española. Disponible online en https://www.rtve.es/alacarta/videos/documentales-b-n/primera-dama-argentina-espana/2848210/ (Visitado el 30-06-2020)

${ }^{66}$ Ibidem.

${ }^{67}$ Ibidem.
} 
Generalísimo, Carmen Polo de Franco. Así, Eva Perón se nos presenta como única en ese espacio. El resto de las mujeres que aparecen en el informativo son bailarinas o artesanas, es decir, mujeres atadas a papeles culturales, folklóricos o tradicionales.

Un elemento que particulariza al NO-DO respecto de la prensa escrita fue la utilización de los noticieros y de la gira española como una plataforma de referencias turísticoeconómicas. El carácter audiovisual permitió que cada uno de los noticieros hiciera una semblanza de los lugares que Eva Duarte visitaba, resaltando los atractivos turísticos y culturales, incluso realizando pequeñas reseñas acerca del desarrollo económico y social. Con ello, realizaba otro tipo de propaganda, centrada, como dice M. Eiroa, en la exposición de las bondades del régimen y su desarrollo pacífico desde el fin de la guerra civil.

\section{La prensa clandestina: la acusación de fascismo.}

A pesar de que la prensa estaba imposibilitada de demostrar cualquier acto de disensión ante la visita de Eva Perón y el tono de los medios fue el ya descrito, sabemos que, desde el extranjero, grupos de exiliados republicanos que abogaban por la caída de Franco en el contexto internacional de repudio a los fascismos tras la Segunda Guerra Mundial, veían con ojo crítico la visita de la argentina. Para las distintas publicaciones opositoras revisadas, la visita de Eva Duarte de Perón a España fue interpretada como un agravio a los sufrimientos vividos por el pueblo español bajo el yugo fascista. En esta lectura, los sentimientos de hermandad hispana no eran más que artilugios discursivos utilizados para esconder las penalidades que vivía y sufría el pueblo español:

"Para mayor prueba y colmo de desvergüenza y de cinismo, está el último viaje "político" de la Sra Duarte de Perón a España, visita que por su significación y por su forma representa un escarnio a los sufrimientos incontables que sufre el pueblo español. (...) La Sra., de Perón en viaje oficioso a España -que Franco ha convertido en viaje 'oficial' e incluso con honores realesseñala bien claramente la solidaridad perniciosa y perversa que existe entre el Gobierno de Perón y la barbarie organizada y venal del régimen de Franco." 68

Sumado a ello, se concluye que, sin el apoyo económico argentino, Franco no sería capaz de sobrevivir al bloqueo político internacional de la postguerra. En este caso, la Argentina estaría prolongando artificiosamente la dictadura de Franco y, con ello, le estaría otorgando la oportunidad de avanzar en un programa de reconversión. En esta línea, la propaganda hispanista, el acercamiento al pueblo y las manifestaciones masivas fueron interpretadas como una estrategia para generar publicidad y apoyo para el Referéndum de sucesión que se celebró poco después de la partida de Eva Perón. Un blanqueamiento de imagen dirigido a las democracias y un acercamiento a América cuyo objetivo estratégico estaría puesto en la integración de España en el Plan Marshall. ${ }^{69}$

Otra crítica importante levantada desde la oposición en el exterior tiene relación con la "oficialidad" del viaje de la primera dama y el despilfarro presupuestario que significó:

\footnotetext{
${ }^{68}$ BVPH, "La Argentina de Perón y la España de Franco", España Popular, Año VIII, Número 351, 20 de junio de $1947,4$.

${ }^{69}$ Ibidem, "El Plan Marshall y sus miras sobre la España franquista", Euzkadi roja: Órgano del Partido Comunista de Euzkadi, Número 47, 26 de junio de 1947, 4.
} 
“¿Cuál es la justificación de ese derroche de lujo, de fiestas palaciegas y de homenajes ruidosos? No queremos entrar en detalles personales sobre la vida de tan singular e intrépida viajera. Pero en todo caso afirmamos que la señora de Perón no puede pretender que ella encarna las grandes tradiciones democráticas. (...) Ser la esposa de un presidente de la República no ha motivado jamás en ningún país recepción tan desbordante. (...) Franco ha querido hacer ver que su régimen no está tan solo, que el desprecio del mundo no es tan absoluto, que aún hay gente de fuera que llegan a rendir la amistad (...) Más la experiencia es comprometedora, no sólo para la señora de Perón en particular, sino para el régimen argentino." ${ }^{\prime 70}$

El compromiso al que alude la cita anterior está relacionado a que la espectacularidad del recibimiento y la gira, más las loas de uno y otro lado, estarían revelando la posición profascista y profalangista de la pareja Perón. Una posición que no era vista como circunstancial, sino que planificada:

“Así como no habido ninguna improvisación en los agasajos oficiales -en esa pompa irritante que ha llegado a ser ridícula por excesiva-, tampoco ha habido ninguna improvisación en los discursos -ni en los actos-de la destacada viajera. Todo muy espectacular, muy ruidoso - a la manera fascista-, Y en cada palabra de alabanza para el franquismo Eva Perón descubría la entraña política de su visita España (...)."

En este sentido, a ojos de los opositores a la dictadura, la visita de Eva Perón ubicaba a Franco a contracorriente del escenario de postguerra, pues la exaltación falangista premeditada en el programa de la visita no ayudaba a los objetivos franquistas de desligarse del halo fascistoide que había delineado la construcción del Nuevo Estado. El viaje, por lo tanto, se interpretó como una afrenta de Franco, en la medida en que públicamente se hizo uso del ceremonial y la simbólica falangista, algunas veces alejada del giro hacia el nacionalcatolicismo que la dictadura española dio durante los años cuarenta:

"Se advierte en la propaganda y en determinados actos del régimen, en estos últimos tiempos (...) Se trata de una palpable reaparición (...) de la influencia de Falange en la vida y el destino de la España franquista. Se trata de una mayor insolencia en la exhibición del carácter fascista del régimen, carácter que con ciertos púdicos velos se intentó ocultar en épocas anteriores."72

Estas críticas al carácter político de la visita y al papel que Argentina tomaba en la defensa del fascismo, se ampliaron con las siguientes escalas que tuvo el viaje de Eva por Europa. En ninguno de los países que visitó posteriormente tuvo un recibimiento ni una publicidad similar a la propiciada en España. Como da cuenta Navarro en su biografía de Eva, abundaron en los partidos de izquierda las críticas abiertas al paso de la primera dama argentina y las acusaciones de defensa de los perdedores de la guerra mundial:

"La publicidad que recibía su viaje creó gran expectativa en los países que debía visitar a continuación, si bien en éstos no faltaron los comentarios desfavorables, tanto antes como después de su llegada. Por lo general, provinieron de partidos socialistas y comunistas. La

\footnotetext{
${ }^{70}$ Ibidem, ¿A qué ha ido a España la Señora Eva Perón? Una gira de propaganda a favor de Franco, Mundo Obrero: Boletín del Partido Comunista de España en Francia, Número 73, 3 de julio de 1947, 3.

${ }^{71}$ Ibidem.

72 Ibidem, "Para los que hablan de evolución democrático cristiana de Franco", España Popular, Año VIII, Número 354, 11 de julio de1947, 3.
} 
izquierda europea, reflejando la posición de la Argentina, continuaba equiparando a Perón con Hitler, y la visita de Evita a España cuando el gobierno de Franco se hallaba aún en cuarentena era la prueba de que no estaba equivocada."73

A Italia, Eva fue una invitada por el gobierno y su logro más importante fue ser recibida por el Papa. En ese país buscó mantener el hilo conductor de su discurso relativo al catolicismo. En entrevistas se declaró contraria al divorcio, aunque defensora del sufragio femenino bajo un discurso maternalista. ${ }^{74}$ Sin embargo, tanto en Roma como en Milán hubo importantes demostraciones de rechazo, como documentan en Mujeres Antifascistas Españolas:

"Doña Eva Duarte, de antecedentes dudosos, esposa del dictador fascista argentino Perón, sale de su país rumbo a Europa. (...) Pero algo le ha sucedido que ella, con su soberbia fascista, no supo prever. (...) Sólo las huestes falangistas, sus Margaritas y el dictador Franco, se han cansado de hacerle reverencias hasta doblar el espinazo. Pero sale de España y llega a Italia, y aquí, las cosas le van de mal en peor. (...) ¿Razones? Los trabajadores, las mujeres de Roma, de Milán, de Nápoles, de todas las ciudades que ha visitado, la han recibido a los gritos de ¡muera Franco!, ¡abajo el fascismo!"75

En Francia, la situación se dio de manera similar. Se produjo un constante desprecio a la visita y la protesta oficial de varios grupos políticos, incluida la Unión de Mujeres Españolas, que rechazaron el recibimiento diplomático de Eva Perón. Se le acusó de no representar a las mujeres argentinas que: “(...) como las mujeres demócratas del mundo entero, están a nuestro lado, están al lado del pueblo español que combate desde hace 11 años contra la tiranía franquista que nos impusieron Hitler y Mussolini y que ha costado a España más de 2 millones de víctimas." 76

\section{La continuidad de la relación hispanista: las Casas María Eva Duarte de Perón.}

Tras el fin de la gira por España, las colonias de argentinos en conjunto con las legaciones diplomáticas regionales conmovidos y orgullosos de la ayuda prestada por su país, sumado al discurso que ponía el ejemplo de la justicia social peronista, impulsaron la creación de una plataforma de ayuda, principalmente sanitaria, para los argentinos y españoles necesitados. De esta iniciativa nacieron centros de atención en salud en Navarra ${ }^{77}$, Valencia ${ }^{78}$, Sevilla $^{79}$, Vigo, Barcelona ${ }^{80}$ y Cádiz $^{81}$, según lo que muestra la documentación de archivo; todos ellos llamados María Eva Duarte de Perón.

${ }^{73}$ NAVARRO, 1994, 144.

${ }^{74}$ Ibidem.

${ }^{75}$ BVPH, "Doña Eva la fascista en retirada", Mujeres antifascistas españolas: boletín publicado por la Unión de Mujeres Españolas, Número 11, julio de 1947, 8

${ }^{76}$ Ibidem, "El paso de la Sra. Eva Perón por Paris", Mujeres antifascistas españolas: boletín publicado por la Unión de Mujeres Españolas, Número 12, septiembre de1947, 6.

${ }^{77}$ AHMREC, Fondo Embajada en Madrid, AH/003, 2 de junio 1948.

${ }^{78}$ Ibidem, AH/004, Valencia, 17 de abril de 1948.

${ }^{79}$ Ibidem, 4 de mayo de 1948.

${ }^{80}$ Ibidem, 18 mayo de 1948.

${ }^{81}$ Ibidem, 5 de junio de 1948. 
Estos consultorios fueron fundados en su mayoría durante 1948 y se dedicaron a suplir carencias en temáticas de salud. La mayoría de ellos fueron levantados tanto por argentinos residentes como por españoles simpatizantes, y algunos no sólo contaban con atención médica, sino que también había apoyo de tipo jurídico y de desarrollo cultural y social. La idea de estos centros de ayuda era replicar en territorio español las políticas peronistas de ayuda a los sectores obreros, en la persecución de la justicia social. La fundación de estas Casas María Eva Duarte de Perón también se imbuyó de la retórica hispanista y de unión entre ambos países que tan fuerte había calado en la propaganda del viaje. Para sus creadores, estas Casas venían a prolongar el lazo de apoyo, como lo vemos reflejado en el discurso inaugural de la Casa de Vigo:

"Mientras en el Mundo se obscurece el horizonte, y los espíritus se atemorizan ante el incierto porvenir; nosotros Argentinos y Españoles, unidos desde hace siglos por la Providencia y por la Historia; y en la orilla de este Mar que presenció atónito hace más de cuatro siglos, como surcaban sus aguas inéditas la trinidad de aquellas quillas españolas; aquí unidos en los mismos ideales altísimos y que por serlo son patrimonio exclusivo de nuestra Raza común; celebramos esta inauguración con el corazón henchido de entusiasmo y gratitud, admiración y respetuoso afecto, por la altísima Dama que allá en la otra orilla de este nuestro Mar, piensa en España con cariño y ternura $(\ldots) "{ }^{82}$

De la misma manera, la no participación de España del Plan Marshall provocó que Argentina se comprometiera con los españoles a través la firma del Protocolo Franco-Perón. La firma de este nuevo tratado que consolidaba los ya firmados, suscitó entre los españoles muestras de agradecimiento que incluso llegaron a cambiar la toponimia del callejero de muchas ciudades en reconocimiento a Perón, su esposa y el pueblo argentino. En febrero de 1948 el Ayuntamiento de Baza en Madrid decide renombrar con el nombre de "Avenida de Perón” a una de las calles colindantes con el Parque José Antonio de esa ciudad "en justo homenaje". El acta de la sesión indica que:

“(...) para manifestar que la Ciudad de Baza se debía considerar obligada a rendir un homenaje de adhesión y entusiasmo a la esclarecida personalidad del Excmo. Sr. D. Juan Domingo Perón (...) no solo porque esta Ciudad, de rancio abolengo español, debe sentir eternamente gratitud a quien $(. .$.$) ha defendido denodadamente ante las grandes potencias mundiales el régimen porque$ felizmente se rige España en la actualidad, sino atendiendo también a que Baza tiene, en cierto modo, la obligación de exaltar a los hijos preclaros de América, como si fuesen suyos propios". ${ }^{8}$

Esta decisión fue seguida por varias ciudades como Sevilla ${ }^{84}$, Madrid $^{85}$, Mahon (Menorca) ${ }^{86}$, Palmas de Islas Canarias ${ }^{87}$ y en Navalmoral de la Mata (Cáceres) ${ }^{88}$ En Cádiz, Perón fue nombrado hijo adoptivo y predilecto de la ciudad. ${ }^{89}$

\footnotetext{
${ }^{82}$ Discurso pronunciado por el Doctor Alfonso González Garra, Médico de Vigo, al inaugurarse el Consultorio. AHMREC, Fondo Embajada en Madrid, AH/004, 30 abril de 1948.

${ }^{83}$ Ibidem, AH/003, 27 de febrero 1948.

${ }^{84}$ Ibidem, AH/006, 17 junio de 1948.

${ }^{85}$ Ibidem, Telegrama No 146,11 junio de 1948.

${ }^{86}$ Ibidem, 2 noviembre de 1948.

${ }^{87}$ Ibidem, AH/009, 22 de octubre 1949.

${ }^{88}$ Ibidem, AH/007 Reservado, 13 de mayo 1948.

${ }^{89}$ Ibidem, 14 mayo de 1948.
} 


\section{Conclusiones}

Como vemos, la visita de Eva Perón constituyó un hito en las relaciones políticas argentino-españolas y el éxito de la visita quedó patente a ambos lados del Atlántico. Las muestras de afecto hacia la primera dama se dieron a lo largo de su viaje y se intensificaron en la medida que Eva generaba instancias de acercamiento al pueblo y demostraba las ayudas sociales y la retórica populista del peronismo. El Embajador Radio una vez finalizada la visita, escribió sobre su éxito a Evita: "Aun vibran los corazones españoles al recuerdo de vuestra belleza juventud e inteligencia. Que el éxito os acompañe en el resto de vuestra gira triunfal son los deseos y los votos que formula esta embajada que os recuerda cariñosa y respetuosamente." 90

La ayuda argentina que tanto espacio ocupó en la propaganda no se prolongó por mucho y hacia principios de los años cincuenta cesó de llegar a España. A pesar de ello, durante el breve lapso en que se mantuvo esta estrecha relación, ambos regímenes obtuvieron beneficios económicos, políticos y propagandísticos, como ya se ha expuesto.

El papel que jugó Eva Duarte en este proceso de acercamiento ha sido analizado por la historiografía como parte del aparato propagandístico que utilizó el franquismo para presentarse internacionalmente en un escenario reticente a su presencia. Hacia la política interior el discurso hispanista y la movilización en apoyo a la visita fue una forma de levantar una nueva faz, volcada al nacionalcatolicismo. Como hemos visto, la figura de Eva fue construida por la prensa a partir de tres nociones: la hispanidad, el catolicismo y la justicia social. En esos espacios se movieron los discursos que encauzaron los eventos a los que asistió y las actividades que realizó.

Además, es importante destacar que la prensa al situarla en el espacio público lo hizo desde una mirada que feminizó su accionar político. Se encargó de relevar aspectos como su belleza, su elegancia, emocionalidad y devoción, construyendo una imagen hispánica femenina en línea con el nacionalcatolicismo. Una imagen que también espectacularizó su visita al convertirla en una exhibición para las masas.

Pese a ello, no podemos desconocer que Eva Perón mantuvo una postura propia que permitió visibilizar el discurso político argentino más allá de la hispanidad, a partir de las estrategias para la construcción de su liderazgo político, como la recurrente cercanía a los sectores trabajadores y desposeídos, la generosidad sin límites, los intentos constantes de contacto verbal y físico, la mención recurrente a Perón. Las consecuencias de este liderazgo y la continuidad de su discurso quedaron plasmadas en la fundación de las Casas María Eva Duarte de Perón, donde las colonias argentinas tomaron como suyos los planteamientos de justicia social.

Es interesante que la prensa opositora editada en el exterior produjo sendas críticas al viaje realizado por Eva Duarte a España y a la postura política tomada por Argentina durante el período. Como vimos, la crítica principal apunta al carácter filo-fascista de la visita y a la oportunidad de sobrevivencia inmerecida que Argentina estaba regalando a Franco.

Por último, la visita de Eva Duarte nos permite dar cuenta de la duplicidad del papel político que se le conminó a interpretar durante su visita en España. Por una parte, el papel del nacionalcatolicismo asignado a las mujeres, centrado en valores conservadores y tradicionales, y por otro, un papel político, protagónico, de mujer que rompe los lindes del

\footnotetext{
${ }^{90}$ Ibidem, AH/004 Telegrama No 41, 27 junio de 1947.
} 
espacio público y privado y que no solo lo hace relacionada al lugar que le otorga la propaganda sino también al propio proceso de empoderamiento político que vive en su país de origen. De este modo, deberíamos entender que el éxito de esta aventura propagandística española no solo se debió a la preparación por parte del régimen español y los deseos de posicionamiento internacional argentino, sino que también a la fuerza de la representación que Eva hace de sí misma y del uso que hace de lo femenino para posicionarse en el espacio público.

\section{REFERENCIAS BIBLIOGRÁFICAS}

Archivos

AHMREC: Archivo Histórico del Ministerio de Relaciones Exteriores y Culto (Argentina) AMINREL: Archivo del Ministerio de Relación Exteriores (Chile)

BNA: Biblioteca Nacional de Argentina

BVPH: Biblioteca Virtual de Prensa Histórica (España)

Fuentes primarias

ABC Madrid, 1947.

Clarín, 1947.

España Popular, 1947.

Euzkadi roja: Órgano del Partido Comunista de Euzkadi, 1947.

Faro de Vigo, 1947.

Mujeres antifascistas españolas: boletín publicado por la Unión de Mujeres Españolas, 1947.

Mundo Obrero: Boletín del Partido Comunista de España en Francia, 1947.

NO-DO, "La primera dama argentina en España", N 232 A, 16-6-1947, en Filmoteca Española,https://www,rtve,es/alacarta/videos/documentales-b-n/primera-damaargentina-espana/2848210/ (Visitado el 30-06-2020).

Bibliografía

BARRANCOS, Dora, Mujeres en la sociedad argentina. Una historia de cinco siglos, Buenos Aires, Sudamericana, 2007.

CERRANO, Carolina, "Las imágenes de la Argentina peronista en la prensa franquista (1945 - 1948)", Revista de Historia Americana y Argentina, 42, 2007, 91-113.

CORREYERO-RUIZ, Beatriz, "La propaganda turística española en los años del aislamiento internacional", Historia y comunicación social, 8, 47-61, 2003.

DEL ARENAL, Celestino, Política exterior de España hacia Iberoamérica. Madrid, Editorial Complutense, 1994.

DELGADO, Lorenzo, Diplomacia franquista y política cultural hacia Iberoamérica, 19391953, Madrid, Centro de Estudios Históricos-CSIC, 1988. 
EIROA SAN FRANCISCO, Matilde, “Acción exterior y propaganda. Las visitas de líderes latinoamericanos a Franco", Latinoamérica, 54, 2012, Vol I, 111-134.

GÓMEZ-FERRER MORANT, Guadalupe, "El viaje de Eva Perón a España”, La Aljaba segunda época, 16, 2012, 15-35.

GONZÁLEZ, Eduardo y LIMÓN, Fredes, La hispanidad como instrumento de combate, Raza e imperio en la prensa franquista durante la Guerra Civil española, España, CSIC, 1988.

GONZÁLEZ DELUCA, María Elena, "Balance de una pasión: ideas para entender las representaciones de Eva Perón", Caravelle, 74, 2000, 191-209.

MAIN, Mary, La mujer del látigo, La Reja, Buenos Aires, 1956.

MICHELOTTI-CRISTRÓBAL, Graciela, "Eva Perón: Mujer, personaje, mito", Confluencia: Revista Hispánica de Cultura y Literatura, 13, 1998, Vol,2, 191-201.

NAVARRO, Marysa, Evita, Buenos Aires, Editorial Planeta, 1994.

"Evita, Historia y Mitología", Caravelle, 98, 2012, 113-133.

PELTA, Raquel, "Eva Perón, icono de la hispanidad", en AZNAR,Yayo y WECHSLER, Diana (Eds), La memoria compartida: España y la Argentina en la construcción de un imaginario cultural (1898-1950), Buenos Aires, Paidós, 165-188, 2005.

PERÓN, Eva, La razón de mi vida, Ediciones Peuser, Buenos Aires, 1951.

POTTHAST, Bárbara, Madres, obreras, amantes--: protagonismo femenino en la historia de América Latina, Madrid, Iberoamericana, 2010.

REIN, Ranaan, "Un salvavidas para Franco: la ayuda económica argentina a la España franquista (1946 - 1949), Anuario del IEHS, 8, 1993, 199-214.

REIN, Raanan, La salvación de una dictadura: Alianza Franco-Perón 1946-1955, Madrid, CSIC, 1995.

RODRÍGUEZ, Florentino y PARDO SANZ, Rosa, "Las relaciones exteriores como factor condicionante del franquismo", Ayer, 33, 1999, 187-218.

THOMÀS I ANDREU, Joan, "La configuración del Franquismo: el partido y las instituciones", Ayer, 33, 1999, 41-64.

ZANATTA, Loris, Eva Perón: Una biografía política, Argentina, Penguin Random House, 2012. 